\title{
Efficacy of nicosulfuron, rimsulfuron and dicamba mixture applied in maize
}

\author{
Skuteczność chwastobójcza mieszaniny nikosulfuronu, \\ rimsulfuronu i dikamby stosowanej z adiuwantami w kukurydzy
}

\author{
Robert Idziak, Zenon Woźnica
}

\section{Summary}

The field experiments were conducted in Brody, near Poznan, during 2011 and 2012 to investigate the effects of time of application and addition of adjuvants on the efficacy of nicosulfuron + rimsulfuron + dicamba and grain yield of maize. The following weed species were investigated Chenopodium album, Fallopia convolvulus, Lycopsis arvensis and Echinochloa crus-galli. Three nicosulfuron + rimsufluron + dicamba application rates were applied with addition of non-ionic surfactant (S), methylated esters (MSO) and ammonium nitrate (AMN). The herbicide mix was applied once at 400 and $200 \mathrm{~g} / \mathrm{ha}$, and twice at 170/170 g/ha with S or MSO and AMN. Evaluated adjuvants provided enhancement of control of reduced rates of nicosulfuron + rimsufluron + dicamba for all weeds. MSO was generally slightly greater effective for weed control than S. Nicosulfuron + rimsufluron + dicamba with adjuvants applied twice at reduced rates greatly increased weed control that ranged between 90 and $100 \%$. Twice application of herbicide mixtures with adjuvants provided slight increase, as compared to other treatments, and high increase, as compare to the untreated treatment, of maize grain yield.

Key words: time of application, herbicide efficacy, adjuvants, weed infestation of maize

\section{Streszczenie}

Badania polowe prowadzono w Brodach pod Poznaniem, w latach 2011-2012, w celu oceny wpływu terminu aplikacji i dodatku adiuwantów na skuteczność zwalczania chwastów mieszaniną nikosulfuron + rimsulfuron + dicamba i plon ziarna kukurydzy. W kukurydzy stwierdzono obecność Chenopodium album, Fallopia convolvulus, Lycopsis arvensis i Echinochloa crus-galli. Nikosulfuron + rimsulfuron + dikamba stosowano w trzech dawkach z dodatkiem surfaktanta niejonowego (S), metylowych estrów (MSO) i saletry amonowej (AMN). Mieszaninę stosowano jednokrotnie w dawce 400 lub $200 \mathrm{~g} /$ ha i dwukrotnie w dawce 170/170 g/ha z S lub MSO i AMN. Badane adiuwanty wpływały na zwiększenie skuteczności mieszaniny nikosulfuron + rimsulfuron + dikamba stosowanej w dawkach zredukowanych, w stosunku do wszystkich chwastów. MSO adiuwant wpływał generalnie korzystniej niż S na działanie herbicydu. Nikosulfuron + rimsulfuron + dikamba stosowane $z$ adiuwantami w dawkach zredukowanych, w systemie dawek dzielonych wpłynęły na wzrost skuteczności chwastobójczej do poziomu 90-100\%. Herbicyd stosowany w systemie dawek dzielonych z adiuwantami prowadził do nieznacznego wzrostu w stosunku do pozostałych kombinacji i znacznego wzrostu plonu ziarna kukurydzy w porównaniu do kontroli.

Słowa kluczowe: termin aplikacji, skuteczność chwastobójcza, adiuwanty, zachwaszczenie kukurydzy

robertid@up.poznan.pl 


\section{Wstęp / Introduction}

Chwasty obecne w łanie kukurydzy zwykle prowadzą do dużych spadków plonu (Idziak i Woźnica 2008; Uremis i wsp. 2009). Okres, w którym obecność niepożądanych gatunków jest najbardziej niekorzystna dla roślin kukurydzy, zależy od liczebności, konkurencyjności gatunków chwastów i czasu ich wschodów (Knezevic i wsp. 2002; Evans i wsp. 2003). Według Hall i wsp. (1992) chwasty należy zwalczać w fazie 3-14 liści kukurydzy, podczas gdy Ferrero i wsp. (1996) wskazują na fazę od 1 do 7 liści, Bedmar i wsp. (1999) od 5 do 7 liści, a James i wsp. (2000) sugerują okres między 4 a 10 tygodniem od siewu kukurydzy. Z kolei według Mahmoodi i Rahimi (2009) okres, w którym należy podjąć działania w celu ograniczenia strat plonu, przypada w fazie od 4 do nawet 17 liści kukurydzy. W Polsce powschodowe zwalczanie chwastów w kukurydzy odbywa się $\mathrm{w}$ fazie od 2 do 7-8 liści (Zalecenia 2010/2011). Większość zalecanych do odchwaszczania kukurydzy herbicydów charakteryzuje się niewielką aktywnością w dłuższym okresie czasu, a zalecana jest do jednokrotnego stosowania w trakcie wegetacji kukurydzy, dlatego istnieje duże prawdopodobieństwo wtórnego zachwaszczenia plantacji. Zbyt wcześnie, ale również zbyt późno wykonany zabieg odchwaszczania może prowadzić do istotnych strat plonu ziarna czy kiszonki kukurydzy. Skutecznym rozwiązaniem jest stosowanie herbicydów, w skład których wchodzi kilka substancji czynnych bądź mieszanin herbicydów oraz ich aplikacja w systemie dawek dzielonych, w dwóch zabiegach, których termin aplikacji wyznaczają kolejne wschody chwastów. W hipotezie roboczej przyjęto, że stosowanie adiuwantów pozwala znacznie obniżyć dawki herbicydów, przy jednoczesnym zachowaniu wysokiej skuteczności chwastobójczej, szczególnie w systemie dawek dzielonych.

Prowadzone badania miały na celu ocenę skuteczności działania mieszaniny nikosulfuron + rimsulfuron + dikamba aplikowanej $\mathrm{w}$ dawkach obniżonych $\mathrm{z}$ dodatkiem surfaktanta bądź metylowanych estrów kwasów tłuszczowych oleju rzepakowego i saletry amonowej oraz ustalenie optymalnego terminu ich stosowania.

\section{Materiały i metody / Materials and methods}

Doświadczenia prowadzono w Zakładzie Doświadczalno-Dydaktycznym Gorzyń, z filią w Brodach, należącym do Uniwersytetu Przyrodniczego w Poznaniu, w latach 2011 i 2012, na glebie płowej o zawartości materii organicznej na poziomie 1,2 i $0,9 \%$ oraz odczynie 6,6 i 4,9. Ocenę skuteczności chwastobójczej wykonano 6 tygodni, a fitotoksyczności 14 i 28 dni po ostatnim zabiegu. Plon ziarna kukurydzy podano dla standardowej zawartości wody w ziarnie na poziomie $15 \%$.

Nasiona kukurydzy odmiany P8100 w ilości 80000 szt./ha siano na poletkach o wymiarach 5 na $2,8 \mathrm{~m}$, w czterech rzędach o rozstawie $70 \mathrm{~cm}$, na głębokość $4 \mathrm{~cm}$. Siew w obu latach wykonano w trzeciej dekadzie kwietnia, z wykorzystaniem siewnika punktowego. Nawożenie mineralne w ilości $60 \mathrm{~kg} /$ ha fosforu i potasu wykonano we wrześniu 2010 i sierpniu 2011 roku. Azot, w obu latach badań aplikowano przedsiewnie w ilości 80 i pogłównie w ilości $60 \mathrm{~kg} / \mathrm{ha}$.

Doświadczenia założono metodą bloków losowanych w układzie niezależnym, w czterech powtórzeniach. Kombinacje badawcze obejmowały mieszaninę nikosulfuronu, rimsulfuronu i dikamby znajdujących się w formulacji preparatu handlowego Hector Max 66,5 WG. Herbicyd stosowano jednorazowo $\mathrm{w}$ dawce rekomendowanej przez producenta - $400 \mathrm{~g} / \mathrm{ha}$ (nikosulfuron $36,8 \mathrm{~g}+$ rimsulfuron 9,5 g + dikamba $220 \mathrm{~g}$ ) oraz w dawkach obniżonych - $200 \mathrm{~g} /$ ha (nikosulfuron 18,4 g + rimsulfuron 4,8 g + dikamba $110 \mathrm{~g}$ ) i $170 \mathrm{~g} /$ ha (nikosulfuron 15,6 g + rimsulfuron 4,0 g + dikamba 93,5 g) z dodatkiem surfaktanta w postaci etoksylowanego alkoholu izodecylowego $\mathrm{S}$ (surfactant) (Trend $90 \mathrm{EC} \mathrm{w}$ dawce $0,1 \%$ ) lub estrów metylowych kwasów tłuszczowych oleju rzepakowego i substancji powierzchniowo-czynnych oraz buforujących pH cieczy opryskowej - MSO (methylated esters) (Atpolan BIO 80 EC w dawce 1,0 1/ha) oraz saletry amonowejAMN (ammonium nitrate) (2 kg/ha). Zabiegi wykonano opryskiwaczem taczkowym o wydatku cieczy roboczej $2301 /$ ha, ciśnieniu $0,22 \mathrm{MPa}$, powschodowo $\mathrm{w}$ fazie 3-5 liści kukurydzy (BBCH 13-15), gdy chwasty już skiełkowały i znajdowały się w fazie siewek do fazy 2-4 liści (A). Terminy zabiegów dzielonych wyznaczały wschody chwastów. Pierwszy z zabiegów dzielonych (B) wykonano, gdy chwasty znajdowały się w fazie liścieni do 1 pary liści, drugi (C) po pojawieniu się kolejnych wschodów chwastów znajdujących się w fazie liścieni do 1 pary liści.

Zebrane dane poddano analizie statystycznej dla doświadczeń czynnikowych ortogonalnych z wykorzystaniem programu Statistica 10. Analiza statystyczna wykluczyła wpływ lat na uzyskane wyniki, dlatego wyniki prezentowane są $\mathrm{w}$ formie średnich $\mathrm{z}$ lat badań, a zróżnicowanie wyników oceniano używając testu Tuckeya przy poziomie istotności $\mathrm{p}=0,05$.

\section{Wyniki i dyskusja / Results and discussion}

W trakcie badań na poletkach doświadczalnych stwierdzono obecność przede wszystkim komosy białej (Chenopodium album L.), rdestu powojowatego [Fallopia convolvulus (L.) Á. Löve], krzywoszyja polnego (Lycopsis arvensis L.) i chwastnicy jednostronnej [Echinochloa crusgalli (L.) P. Beauv.]. Na ich dominującą rolę w kukurydzy wskazują także inni autorzy (Dąbkowska i wsp. 2007). W zbiorowisku chwastów stwierdzono ponadto, w niewielkim nasileniu, obecność rdestu ptasiego (Polygonum aviculare L.), bodziszka drobnego (Geranium pusillum L.), przetacznika bluszczykowego (Veronica hederifolia L.), jasnoty purpurowej (Lamium purpureum L.), iglicy pospolitej [Erodium cicutarium (L.) L`Her.], przetacznika perskiego (Veronica persica Poir.), dymnicy pospolitej (Fumaria officinalis L.), bylicy pospolitej (Artemisia vulgaris L.) i ostrożenia polnego [Cirsium arvense (L.) Scop.]. Skład gatunkowy zbiorowisk chwastów w zależności od lokalizacji, warunków pogodowych i glebowych ulega zmianom, a występujące w doświadczeniu gatunki chwastów można uznać za często spotykane 
w łanie kukurydzy (Tański i Idziak 2009; Kierzek i wsp. 2011).

Mieszanina nikosulfuron + rimsulfuron + dikamba stosowana jednokrotnie w dawce zalecanej $400 \mathrm{~g} / \mathrm{ha}$ $\mathrm{z}$ dodatkiem surfaktanta lub estrów metylowych kwasów tłuszczowych skutecznie ograniczała występowanie Ch. album, odpowiednio 93 i 96\% (tab. 1). Redukcja dawki do połowy zalecanej wpłynęła na silny spadek efektywności zabiegu wykonanego mieszaniną nikosulfuron + rimsulfuron + dikamba $+\mathrm{S}(71 \%)$, a niewielki w przypadku mieszaniny $\mathrm{z}$ dodatkiem MSO (92\%). Saletra amonowa włączona do cieczy opryskowej zawierającej nikosulfuron + rimsulfuron + dikamba $+\mathrm{S}$ spowodowała poprawę efektywności zabiegu (wzrost do 85\%), w przypadku mieszaniny nikosulfuron + rimsulfuron + dikamba + MSO skuteczność chwastobójcza nie uległa większym zmianom. Zabieg mieszaniną nikosulfuron + rimsulfuron + dikamba w dawce zalecanej z dodatkiem S lub MSO pozwalał efektywnie ograniczyć występowanie $F$. convolvulus (tab. 1). Redukcja dawki badanej mieszaniny do $200 \mathrm{~g} / \mathrm{ha}$ skutkowała obniżeniem skuteczności chwastobójczej, niezależnie od stosowanego adiuwanta. Dodatek adiuwanta mineralnego $\mathrm{w}$ formie saletry amonowej prowadził do dalszego spadku skuteczności zabiegu, silniejszego w przypadku mieszaniny, w skład której wchodziły estry metylowe. Badana $\mathrm{w}$ doświadczeniu mieszanina skutecznie ograniczała występowanie L. arvensis. Obniżenie dawki prowadziło do spadku efektywności zabiegu do 85 i 90\% (odpowiednio, nikosulfuron + rimsulfuron + dikamba $+\mathrm{S}$ i MSO). Dodanie do mieszaniny adiuwanta mineralnego saletry amonowej pozwalało praktycznie całkowicie wyeliminować $L$. arvensis $\mathrm{z}$ łanu kukurydzy (tab. 1). Soltani i wsp. (2010) oraz Isaacs i wsp. (2002) wskazują na wysoką efektywność mieszaniny zawierającej nikosulfuron i rimsulfuron w ograniczaniu występowania chwastów dwuliściennych, w tym Ch. album, szczególnie gdy w formulacji środka znajduje się także dikamba.

Tabela 1. Wpływ adiuwantów i terminów aplikacji na skuteczność chwastobójczą herbicydu stosowanego w kukurydzy Table 1. Influence of adjuvants and time of application on efficacy of herbicide applied in maize

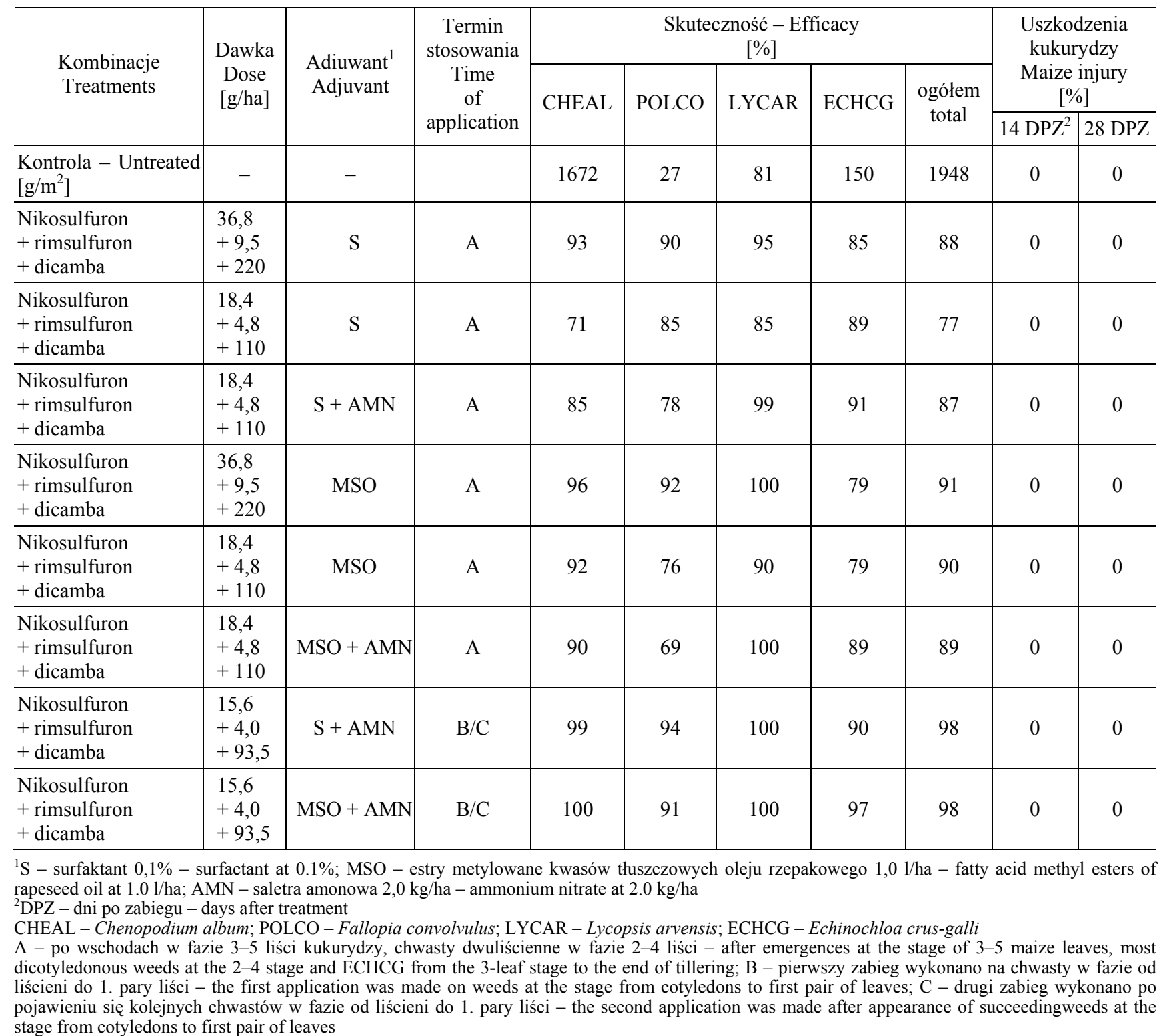




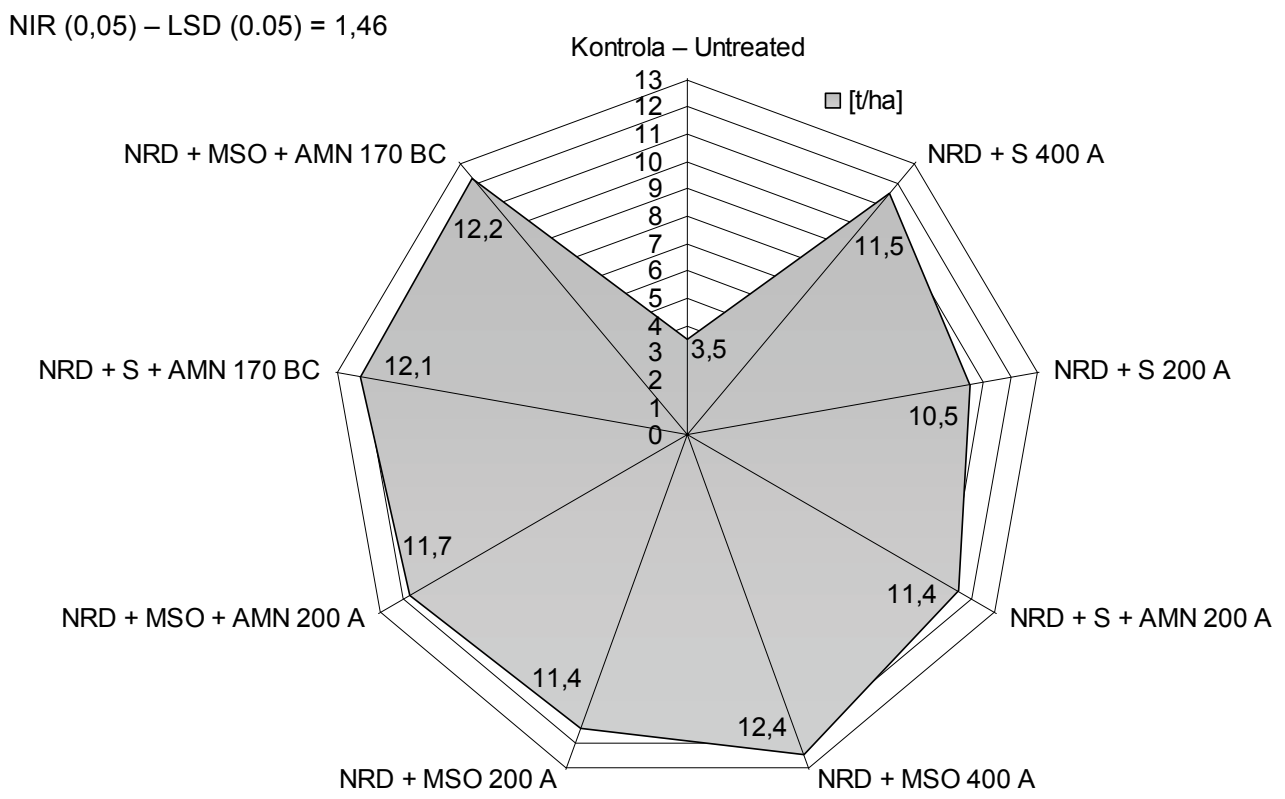

Rys. 1. Wpływ surfaktanta (S), estrów metylowych kwasów tłuszczowych oleju rzepakowego (MSO), saletry amonowej (AMN) $\mathrm{i}$ terminów aplikacji $(\mathrm{A}, \mathrm{B} / \mathrm{C})$ mieszaniny nikosulfuron + rimsulfuron + dikamba (NRD) na plon ziarna kukurydzy [t/ha]

Fig. 1. Influence of surfactant (S), fatty acid methyl esters of rapeseed oil at (MSO), ammonium nitrate (AMN) and application time (A, $\mathrm{B} / \mathrm{C}$ ) of mixture of nicosulfuron + rimsulfuron + dicamba (NRD) on grain yield of maize [t/ha]

NIR - najniższa istotna różnica - LSD - least significant difference

Zwalczanie E. crus-galli było efektywniejsze w przypadku mieszaniny zawierającej oprócz nikosulfuronu + rimsulfuronu + dikamby także surfaktant, niezależnie od dawki herbicydu. Efektywne wyeliminowanie E. crus-galli mieszaniną z dodatkiem MSO miało miejsce, gdy w cieczy znajdowała się także saletra amonowa. Mieszaniny nikosulfuron + rimsulfuron + dikamba $+\mathrm{S}$ lub MSO z dodatkiem AMN, w systemie dawek dzielonych były bardzo skuteczne w zwalczaniu E. crus-galli, szczególnie gdy w skład mieszaniny wchodziło MSO (tab. 1). Skuteczne eliminowanie z łanu kukurydzy E. crus-galli wynika, przede wszystkim z jej dużej wrażliwości na rimsulfuron (Koeppe i wsp. 2000) i nikosulfuron (Idziak i wsp. 2010) oraz odpowiednio dobranych adiuwantów (Auskalniene i Auskalnis 2006).

Wyniki zwalczania chwastów ogółem wskazują, że generalnie korzystniej na aktywność biologiczną mieszaniny zawierającej nikosulfuron + rimsulfuron + dikamba wpływał dodatek adiuwanta na bazie estrów metylowych (MSO) - skuteczność na poziomie $89-91 \%$. Obecność w cieczy opryskowej adiuwanta o charakterze surfaktanta, szczególnie w obecności AMN, pozwalało ograniczyć występowanie chwastów, podobnie jak mieszanina stosowana $\mathrm{W}$ dawce zalecanej. Zredukowanie dawki o $50 \%$ z dodatkiem jedynie S przekładało się na wyraźny spadek efektywności zabiegu.

Chwasty obecne w łanie kukurydzy (obiekt kontrolny) silnie ograniczyły plon ziarna kukurydzy, do 3,5 t/ha. Zwalczanie chwastów przyczyniło się do istotnego wzrostu plonu ziarna. Najwyższy plon uzyskano na obiekcie, na którym mieszaninę nikosulfuron + rimsulfuron + dikamba stosowano $\mathrm{w}$ dawce zalecanej $\mathrm{z}$ dodatkiem MSO $\mathrm{w}$ jednym zabiegu $(12,4 \mathrm{t} / \mathrm{ha})$. Plon ziarna na pozostałych obiektach badawczych wahał się od 11,4 do 12,2 t/ha, przy czym nie stwierdzono różnic $\mathrm{w}$ wysokości plonu ziarna pomiędzy tymi obiektami badawczymi. Plon ziarna istotnie niższy od najwyższego stwierdzono na obiekcie traktowanym mieszaniną nikosulfuron + rimsulfuron + dikamba $\mathrm{w}$ dawce zredukowanej do $200 \mathrm{~g} / \mathrm{ha} \mathrm{z}$ dodatkiem surfaktanta (rys. 1). Mieszanina nikosulfuron + rimsulfuron + dikamba, niezależnie od dawki, terminu stosowania i dodatku adiuwantów, nie powodowała uszkodzeń roślin kukurydzy (tab. 1).

Uzyskane wyniki oraz doniesienia literaturowe wyraźnie wskazują, że jednym z najistotniejszych czynników wpływających na działanie herbicydów jest faza rozwojowa chwastów w momencie zabiegu (Woźnica 2008; Chauhan i Abugho 2012). Z kolei na kiełkowanie i rozwój chwastów wpływają warunki pogodowe (James i wsp. 2006; Gołębiowska i Snopczyński 2008). Kierzek i wsp. (2011) stwierdzają że nierównomierne wschody w czasie, różnych gatunków chwastów, spowodowane w głównej mierze przebiegiem warunków pogodowych, także wywierają wpływ na końcowy efekt chwastobójczy. Stosowanie herbicydów w dwóch terminach, na chwasty w bardzo wczesnych fazach rozwojowych, w okresie ich największej wrażliwości, jest dobrym rozwiązaniem pozwalającym, nie tylko bardzo skutecznie eliminować chwasty, ale także podnieść efektywność ekonomiczną zabiegów (Woźnica i Idziak 2010). Prezentowane wyniki wskazuja, że stosowanie znacznie zredukowanych dawek herbicydów $\mathrm{z}$ dodatkiem surfaktanta lub metylowych estrów w obecności saletry amonowej, w systemie dawek dzielonych, aplikowanych na chwasty we wczesnych fazach rozwojowych gwarantuje wysoką skuteczność chwastobójczą zabiegu i ochronę łanu kukurydzy przed kolejnymi wschodami chwastów. 


\section{Wnioski / Conclusions}

1 Aplikacja mieszaniny nikosulfuron + rimsulfuron + dikamba w dwóch terminach, w dawkach obniżonych o $58 \%$ w stosunku do dawki zalecanej, z dodatkiem surfaktanta lub metylowych estrów kwasów tłuszczowych gwarantowała efektywną ochronę kukurydzy przed chwastami.
2. Mieszanina nikosulfuron + rimsulfuron + dikamba niezależnie od dawki, terminów stosowania i dodatku adiuwantów nie powodowała uszkodzeń roślin kukurydzy.

3. Zastosowanie mieszaniny herbicydów w zredukowanych dawkach $\mathrm{z}$ adiuwantami i saletrą amonową, w formie zabiegu jednokrotnego, a szczególnie w systemie dawek dzielonych w dwóch zabiegach, sprzyjało plonowaniu kukurydzy.

\section{Literatura / References}

Auskalniene O., Auskalnis A. 2006. Effect of sulfonylurea herbicides on weeds and maize. Agron. Res. 4: 129-132.

Bedmar F., Manetti P., Monterubbianesi G. 1999. Determination of critical period of weed control in corn using a thermal basis. Pesq. Agropec. Bras. Brasilia 34: 187-193.

Chauhan B.S., Abugho S.B. 2012. Effect of growth stage on the efficacy of posemergence herbicides on four weed species of directseeded rice. The Scientific World J., article ID 123071: 1-7.

Dąbkowska T., Stupnicka-Rodzynkiewicz E., Bintsanga-Malounguidi P. 2007. Wpływ warunków pogodowych i zabiegów odchwaszczających na rozwój chwastów w kukurydzy, ze szczególnym uwzględnieniem Echinochloa crus-galli. Ann. UMCS Sectio E, 42 (2): 117-126.

Evans S.P., Knezevic S.Z., Lindquist J.L., Shapiro C.A., Blankenship E.E. 2003. Nitrogen application influence the critical period for weed control in corn. Weed Sci. 51: 408-417.

Ferrero A., Scanzio M., Acutis M. 1996. Critical period of weed interference in maize. p. 171-176. Proc. 2nd Int. Weed Control Congress. Copenhagen, June 25-28, 1996, 762 pp.

Gołębiowska H., Snopczyński T. 2008. Wzrost zagrożenia zachwaszczeniem wtórnym na plantacji kukurydzy na tle zróżnicowanego przebiegu pogody. [The increase of secondary weed infestation threat on maize crop fields in relation to changing weather conditins]. Prog. Plant Prot./Post. Ochr. Roślin 48 (2): 602-611.

Hall M.R., Swanton C.J., Anderson G.N. 1992. The critical period of weed control in grain corn (Zea mays L.). Weed Sci. 40: $441-447$.

Idziak R., Woźnica Z. 2008. Skuteczność chwastobójcza herbicydu Callisto 100 SC stosowanego z adiuwantami i nawozem mineralnym. Acta Agrophys. 11 (2): 403-410.

Idziak R., Waligóra H., Skrzypczak W. 2010. Ocena skuteczności chwastobójczej mieszaniny mezotrion + nikosulfuron stosowanej $\mathrm{z}$ adiuwantami w kukurydzy cukrowej. [Evaluation of mesotrione + nicosulfuron efficacy applied with adjuvants in sugar maize]. Prog. Plant Prot./Post. Ochr. Roślin 50 (1): 303-307.

Isaacs M.A., Wilson H.P., Toler J.E. 2002. Rimsulfuron plus thifensulfuron-methyl combinations with selected postemergence broadleaf herbicides in corn (Zea mays). Weed Technol. 16: 664-668.

James T.K., Rahman A., Mellsop J.M. 2000. Weed competition in maize crops under different timings for post-emergence weed Control. N. Z. Plant Prot. 53: 269-272.

James T.K., Rahman A., Trolove M. 2006. Optimal timing for post emergence applications of nicosulfuron for weed control in maize. N. Z. Plant Prot. 59: 250-254.

Kierzek R., Miklaszewska K., Krawczyk R., Matysiak K. 2011. Wpływ terminu nalistego stosowania w kukurydzy mieszanin herbicydów na ich efektywność chwastobójczą. [Effect of the foliale application date of herbicide mixtures on weed control in maize]. Prog. Plant Prot./Post. Ochr. Roślin 51 (4): 1836-1841.

Knezevic S.Z., Evans S.P., Blankenship E.E., van Acker R.C., Lindquist J.L. 2002. Critical period for weed control: The concept and data analysis. Weed Sci. 50: 773-786.

Koeppe M.K., Hirata C.M., Brown H.M., Kenyon W.H., O'Keefe D.P., Lau S.C., Zimmerman W.T., Green J.M. 2000. Basis of selectivity of the herbicide rimsulfuron in maize. Pest. Biochem. Physiol. 66: 170-181.

Mahmoodi S., Rahimi A. 2009. Estimation of critical period for weed control in corn in Iran. World Acad. Sci. Engin. Technol. 49: 67-72.

Soltani N., Shropshire C., Sikkema P.H. 2010. Adjuvant comparison for postemergence weed control in corn. 90 (4): $543-547$.

Tański M., Idziak R. 2009. Wpływ terminów regulacji zachwaszczenia na skuteczność chwastobójczą herbicydów i plon kukurydzy. [Influence of weed control regulation on herbicide efficacy and grain yield of mazie]. Prog. Plant Prot./Post. Ochr. Roślin 49 (1): 349-352.

Uremis I., Uludag A., Ulger A.C., Cakir B. 2009. Determination of critical period for weed control in the second crop corn under Mediterranean conditions. Arf. J. Biotechnol. 8 (18): 4475-4480.

Woźnica Z. (red.). 2008. Aplikacja, skuteczność chwastobójcza i selektywność herbicydów. s. 255-293. W: „Herbologia. Podstawy biologii, ekologii i zwalczania chwastów". PWRiL, Poznań, 430 ss.

Woźnica Z., Idziak R. 2010. Influence of herbicide application timings, rates and adjuvant type on weed control and yield of maize grown for forage. Acta Sci. Pol., Agricultura 9 (4): 77-84.

Zalecenia Ochrony Roślin na lata 2010/2011. Cz. II, Rośliny Rolnicze. 2010. Inst. Ochr. Roślin, Poznań: 113-117. 